\title{
A MODEL FOR MEASURING THE IMPACTS OF INFLATION ON MOTOR INSURANCE BUSINESS
}

\author{
by \\ Jean-Marc BeLLoY * and André GABUS **
}

\section{INTRODUCTION}

One of the consequences of accelerating inflation is its disturbance of the economic decision process inherent in insurance company operations, especially because of the latter's increasing complexity. As is often the case with complex systems, partial solutions have been worked in different sections of the business. They have a practical value in the very environment where they are used but they lack integration. As the aim of a mathematical model is to formulate an integrated point of view, such a model can aid in a better understanding of this complexity and in exploring the repercussions of what is a relatively new situation for the European economies. The use of such a model, however, presupposes a certain level of familiarity with these kind of methods. This familiarity can be rapidly acquired if the model is sufficiently simple.

The GIM model ${ }^{1}$ used for the simulation exercise conducted for a group of European companies constitutes the first step in the construction of a microeconomic model which should be individually tailored to the specific requirements of the firm.

The purpose of the simplified simulation model presented here is more modest ; its use can be considered as a learning process generally available to insurance companies to improve their understanding of the effects of inflation in their business operations.

* Applied mathematician, Battelle, Geneva Research Centre.

** Economist, Battelle, Geneva Research Centre.

1 Stands for the "Geneva Insurance Model". 
The main difficulty to study the influence of inflation is its direct or indirect and unequal influence on nearly every aspects of insurance business, among them :

- claims costs,

- operating expenses,

- premiums calculations,

- investment income,

- size of provisions,

- level of profit necessary to maintain reserves while paying a reasonable dividend to shareholders.

Further, the problems resulting from inflation are not only tied to the rate of increase in prices, but also depends on the realtive time lags of the adjustments in revenues.

Among the relevant factors that are highlighted in the present study are :

- the lag in adjustment of premiums,

- the lag in adjustment of investment returns,

- the lag in the settlement of claims,

- the lag in the modification of operating costs.

Because of these time lags of varying duration, the financial position of an insurance company may rapidly change from profits to losses.

The GIM model was developed from the standpoint of a typical insurance company dealing in personal and property damage, and provides the facility for studying the results of the variations in time lags and rates of inflation selected by the model user.

\section{SCOPE OF THE STUDY}

During a meeting in December 1974 held in Geneva with the participation of Professor D. Farny from Köln University, Miss G. Ferrara, actuary, Assicurazioni Generali, Trieste, Mr. H. Loubergé, Assistant at the University of Geneva, Mr. O. Giarini, executive secretary of AIEEA ${ }^{1}$, the aims and scope of the study, as well as the general features of the model, were discussed and approved. These may be described as follows :

\footnotetext{
1 For the "Association Internationale pour l'Etude de l'Economie des Assurances", called "the Geneva Association".
} 
1. The research is to be carried out for a company specialised in automobile insurance.

2. For the sake of simplicity, only one type of insurance policy, broken down into three categories of vehicles and two types of damages, will be considered.

3. The model is to be used with net figures (for example, in the case of premiums : premiums net of commissions, and for investments : yield on investment net of commissions).

4. The investment portfolio is to be - as far as possible - broken down into at least four types of investments (the model considers actually six types of investments) and for each, when possible, has to show not only the yield but also the market value.

5. As this is an economic model intended to highlight the effects of inflation, the concepts of value at constant prices are to be used in conjunction with price (or cost) indices.

\section{OUTLINE OF THE MODEL}

Motor insurance or any other non-life insurance business can only be harmoniously developed by balancing its commercial development, the risk management aspect of its activities and its financial operations. As inflation is influencing all three of these activities and since the aim of the model is to measure the very disequilibrium induced by inflation, the structure of the model reflects the division of insurance business with these three aspects.

The commercial aspect is mainly concerned with the premiums portfolio, i.e. the number of premiums earned by category of vehicles and, in each category, the product mix of various policy types (expressed by the average constant value of one policy) and the premium price index of those policies ${ }^{1}$. The price of premiums is one of the instruments an

1 Let us recall that, by definition, this price index is representing the ratio of the price of a premium in year $t$ over the value that would have been paid in base year (in our case base year is 1970) for the same premium, assuming that the risk content is exactly the same. This concept widely used by economists is very useful to dissociate the pure price effect from all other changes.

Using this concept, the actuarial influence of the claim frequency and the nature or importance of claims on the value of premiums should be its constant price value, while the price index of claims should only be affected by the change in cost of claims due to inflation. 
insurance company can use to compensate the negative effects of inflation on its balance sheet. This instrument is however not of unlimited use in vehicles insurance business, because insurance premiums are generally set in very competitive conditions, thus depending largely on market conditions and, in many countries, their price increases are also subject to governmental approval. For these reasons it was assumed that the premium price was bound to vary more or less in line with inflation with a few years lag.

To allow simulation of several hypothesis of lags in premiums price adjustment to inflation, the change in premium price index has been assumed to be a linear function of inflation lagged up to four years. That is : the price index on premiums $p_{t}$ in year $t$ is calculated as :

$$
p_{t}=p_{t-1} \cdot\left(1+\beta+\alpha_{0} I_{t}+\alpha_{1} I_{t-1}+\alpha_{2} I_{t-2}+\alpha_{3} I_{t-3}+\alpha_{4} I_{t-4}\right)
$$

where $I_{t}$ is the inflation rate in year $t$ and $\beta, \alpha_{0}, \alpha_{1}, \ldots, \alpha_{4}$ are coefficients.

Setting all the $\alpha$ 's equal to zero, it is possible through the $\beta$ coefficient to simulate any exogenously-given adjustment in premium prices.

Setting for instance $\beta=0.03$ (three percent), $\alpha_{0}=\alpha_{1}=\alpha_{3}=\alpha_{4}=0$ and $\alpha_{2}=1$ allows the simulation of adjustment of premiums three percent higher than inflation with a lag of two years.

The net premiums earned is assumed to be proportional to the number of vehicles insured and to the mean value of premiums, this value being further disaggregated into its constant price value and its price index, i.e. :

$$
\begin{aligned}
& \text { Premiums earned }= \text { premium number } \times \text { mean value of a premium } \\
& \text { at constant price } \times \text { price index of premium. }
\end{aligned}
$$

The number of premiums, reflecting the importance of business, has been kept exogenous to the model. This permits making various simulations of the impact of change of inflation on insurance companies under different hypothesis of growth in business.

The risk management activity deals with the claims, their number being equal to the product of the number of premiums by the frequency of damage by category of vehicle and type of damage (bodily or material). The importance of damage (by type of claims) is taken into account by their average cost at constant prices and the structure of these costs (the 
structure of cost is the distribution of cost into: wages, compensation for property losses, compensation for disability or death, medical care). Thus :

Number of claims $=$ number of premiums $\times$ frequency of damage.

For the sake of simplicity, and according to the agreement specifying that we work with net figures, the number of claims as well as the cost of damages defined in the model represents the number of claims and the cost net of these disallowed, irrespective of the fact if they have been reported or not. We have :

$\begin{aligned} \text { Cost of claims at constant price }= & \text { number of claims } \times \text { average } \\ & \text { cost at constant price. }\end{aligned}$

This total cost of claims in year $t$ at constant price, represents what would have been the cost of those same claims if they had all been settled in the base year (1970); they are a kind of measure of importance of losses independent from price changes.

As the claims are not settled immediately, and as delay causes the cost of settlement to rise in times of inflation because the costs are related to price level prevailing at the time of settlement, we have introduced for each year $t$ of incurrence of claims a schedule of settlement. The settlement of damages is calculated with this exogenously given schedule of settlement for each year of incurrence and by type claims (bodily, material). The price of claims settled is readjusted each year according to the structure of costs and the price index of each of its components; it is then applied to the claims settled during the year, whatever the date of incurrence.

Let us call $r_{t}$ the total claims paid in year $t, d^{h}$ the cost at constant price of claims incurred in year $h$ and $p c_{t}$ the cost index of claims in year $t$.

If $f^{h}$ is the schedule of settlement for claims incurred in year $h$ and $f_{t}^{h}$ is the part of those claims paid in year $t\left(t \geqslant h\right.$ and $\left.\sum_{t} f_{t}^{h}=1\right)$, then
total claims paid during year is:

$$
r_{t}=p c_{t} \cdot \sum_{h} d^{h} f_{t}^{h}
$$

The provision for outstanding claims being equal to the value of future payments for claims that have already incurred, their number and 
their importance are known (cost of damage at constant price) while their cost value is depending on future inflation. For this reason one needs to anticipate future inflation and reevaluate provisions every year according to the new expectation of inflation.

People's expectations being influenced by past experience, computation of expected inflation at time $t$ is based on a weighted average of past (observed) inflation. As the forecast considers years more distant from time $t$, the weights applied to past inflation move from the preponderant weighting of more recent observations to something resembling a normal arithmetic mean, namely :

$$
e_{t}^{t+\ell}=\gamma_{t}^{\ell}+\sum_{i=t-4}^{t} \omega_{i+5-t}^{\ell} \cdot I_{i}
$$

where $I_{i}$ is inflation observed in year $i$ and $e_{t}^{t+\ell}$ is inflation expected in year $t$ for future year $t+\ell$. This expression assumes that anticipation of future inflation is mainly dependent of the last 5 years experience, the weights of those years being given by the coefficient $\omega$, while the $\gamma$ coefficient allows the introduction of exogenous corrections to simulate other behaviour, i.e. pessimistic or optimistic views of the future.

The financial part of the model calculates the rate of return by type of investments (building, shares, participation, bonds, mortgage, loans) as well as the market value of those investments, both of which are influenced by present and past inflation rates. Through sales and purchases of assets one can modify the overall return on investment and generate gains (or losses) on those capital transactions.

Functioning of the model involves three additional technical aspects :

- the calculation of operating costs which takes into account the evolution of wages,

- the evaluation of payment of taxes and dividends,

- the calculation of inflows and outflows of cash.

Links between the various parts of the model are shown on the simplified diagram (see Fig. 1, page 11). 


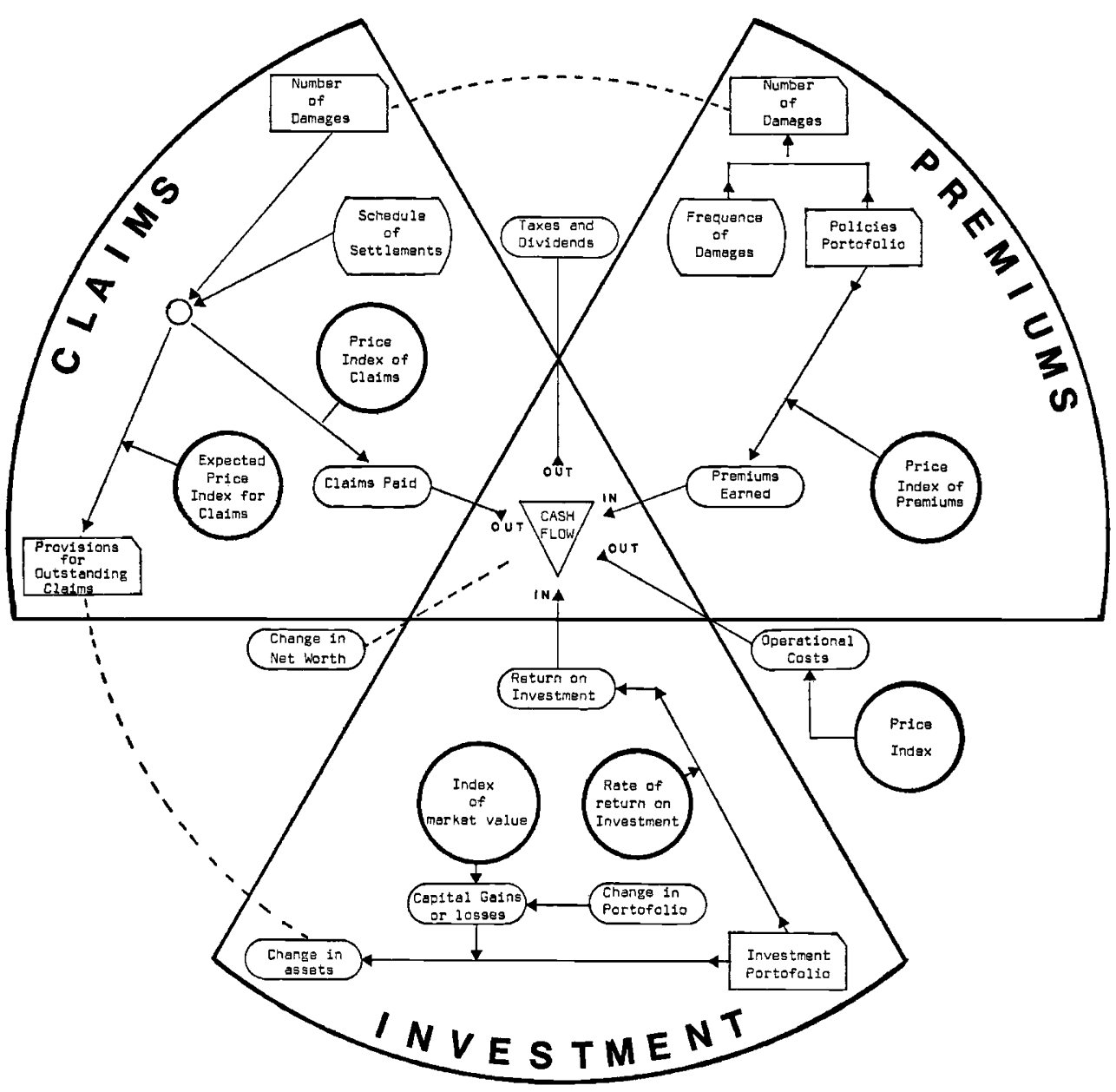




\section{MAIN INDICATORS OF RESULTS}

The effects of inflation on personal and property damage insurance business can be appreciated on the basis of two general indicators and four specific ratios. We will consider here :

(i) the gross profits before tax,

(ii) the net worth,

(iii) the return on invested capital,

(iv) the solvency margin,

(v) the loss ratio,

(vi) the ex-post cost of claims ratio.

The gross profits before tax are made of the profits (as shown in the Operation Account in Annex 1), plus the taxes paid and the distributed profits. For simplicity's sake, tax and dividends paid are proportional to gross profits; the rate chosen ( 30 per cent) gives a sizable amount of profits retained.

The net worth is equal to the total assets at market price less the provisions for outstanding claims. Profits retained (as shown by the Carry Forward item of the Balance Sheet in Annex 1) and Capital Gains (as shown on the same Balance Sheet) roughly contribute equally to the growth of net work.

The percentage of gross profits before tax over the net worth gives an indication of the return on capital invested in the company. No change in shareholder's capital is supposed to take place during the simulation period 1975-1985.

The solvency margin is defined as the ratio of net worth over premiums earned. It should be higher than 1 .

The so-called loss ratio is also widely used in insurance companies for the measurement of efficiency and as a basis for the prediction of future results. This ratio measures the sum of payments of claims for a given year regardless of their date of incurrence over the premiums earned during the same year. It is easily measurable and represents roughly the ratio of cash-in over cash-out.

This is a fairly good indicator for an insurance company when the volume of business and inflation are constant or growing at steady rates. However, for comparing the results of several companies or the per- 
formance of a single company at different periods when the volume of business and inflation are changing, this indicator can be misleading.

On the other hand as delay in settlement leaves additional investment funds in the hand of the company (provision for outstanding claims) and allows for extra interest to be earned, those returns should also be accounted for in order not to overstate the real cost of claims for the company.

For these reasons we have also given another indicator which is the ratio of the actualised sum paid ${ }^{1}$ over the years for claims incurred in a given past year $t_{0}$ over the premiums earned in the same year $t_{0}$ (ex-post cost of claims ratio).

This indicator takes into account observed cost of claims as well as the return on investments (including losses or gains on capital transactions). It represents the ratio of the sum of money necessary for the payment of claims incurred in a given year over the amount actually earned in the same year.

This indicator is independent of the volume of business; it is also independent of inflation as far as the rate of return on investment matches the rate of increases of cost of claims. Unfortunately this indicator can only be computed ex-post, i.e. once most of the claims are settled. It is however very useful to highlight disequilibrium that has been overlooked, due to the covering influence of other factors (like growth in the volume of business), and could endanger the company in the future.

\section{RESULTS}

\section{The historical and standard runs}

The model was run on an historical basis from 1970 to 1974 (historical run). From 1975 onwards it was run according to a "no change" general assumption, except for inflation (the standard run was designed

1 "Actualised sum paid" means the sum paid less a discount for interest earned on it during the time elapsed between incurrence of claim and its settlement. The rate of interest is the one observed on investments including losses or gains on capital transaction. 


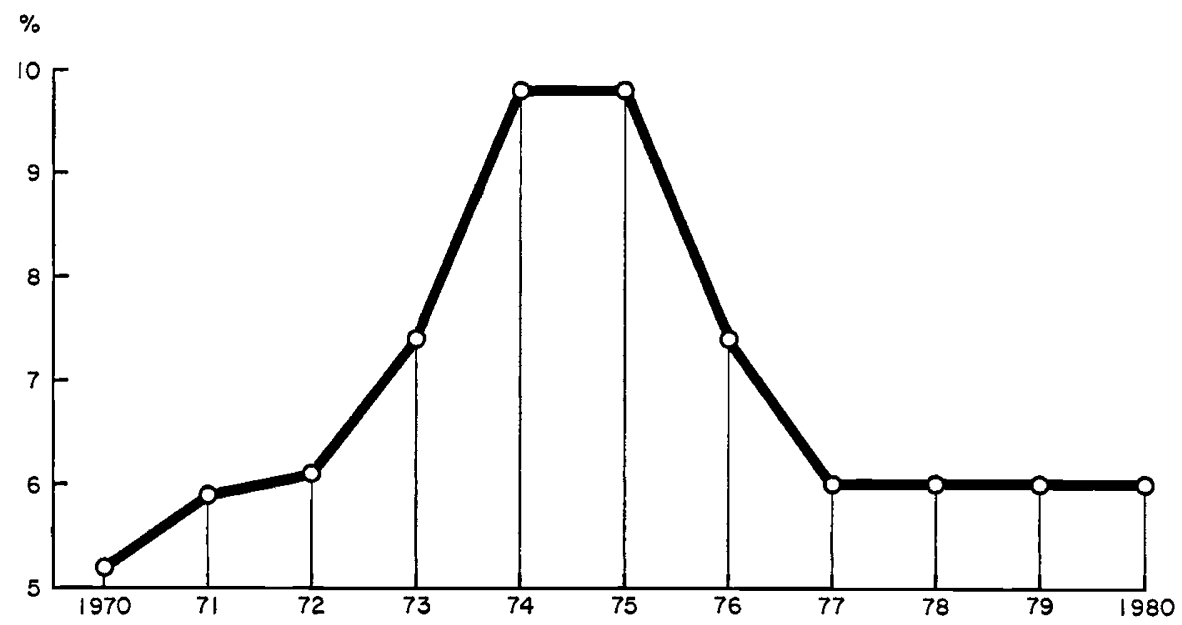

to be used as a reference output for comparing results obtained with alternative inputs).

As shown on Fig. 2, inflation is supposed to stop increasing in 1975 and to decrease in 1976 and 1977 ; from 1978 onwards the rate is assumed to be maintained at $6 \%$, i.e. one per cent over the historical rate of $5 \%$ in France during the $1950-1970$ period.

No assumption was made on the impact of inflation on business volume. The premiums portfolio is supposed to remain constant at its 1974 level during the whole standard run covering the simulation period $1975-1980^{1}$. The model was run up to 1985 to explore the acceleration of the disequilibrium induced by inflation.

Values of the six selected indicators (see Section IV above) are given below for typical year of the historical and standard runs (Table 1).

1 The price of premiums is supposed to increase at the mean value of inflation observed the two previous years, i.e. the premium price is adapting to inflation with a $11 / 2$ year lag (this is expressed by setting $\beta=\alpha_{0}=\alpha_{3}=\alpha_{4}=0$ and $\alpha_{1}=\alpha_{2}=0.5$ in the calculation of premium price p. 8 ). 
Table 1. Main Indicators of Results of the Historical and Standard Runs

\begin{tabular}{|c|c|c|c|c|c|c|}
\hline Years & $\begin{array}{l}\text { Gross } \\
\text { Profits } \\
\text { before } \\
\text { Tax } \\
\text { (in Mio }\end{array}$ & $\begin{array}{l}\text { Net } \\
\text { Worth }\end{array}$ & $\begin{array}{l}\text { Return on } \\
\text { Invested } \\
\text { Capital } \\
\text { (in \%) }\end{array}$ & $(1 .=$ nor & $\begin{array}{l}\text { Loss * } \\
\text { Ratio } \\
\text { (\%) }\end{array}$ & $\begin{array}{l}\text { Ex-post } \\
\text { Cost of } \\
\text { Claims } \\
\text { Ratio } \\
(\%)\end{array}$ \\
\hline 1970 & 4.5 & 101.3 & 4.4 & 1.23 & 81.5 & 90.4 \\
\hline 1974 & 0.0 & 116.1 & -.- & 1.00 & 81.7 & 93.3 \\
\hline 1975 & 0.4 & 121.6 & 0.3 & 0.94 & 79.2 & 90.9 \\
\hline 1977 & 17.3 & 153.3 & 11.3 & 1.00 & 78.7 & 90.4 \\
\hline 1979 & 7.7 & 177.9 & 4.3 & 1.02 & 81.5 & 94.5 \\
\hline 1980 & 3.4 & 185.6 & 1.8 & 1.01 & 83.4 & 97.0 \\
\hline 1981 & -2.0 & 186.8 & -..- & 0.96 & 85.5 & 99.6 \\
\hline 1985 & -37.0 & 111.1 & -.- & 0.45 & 94.8 & 105.1 \\
\hline
\end{tabular}

Fluctuations in profits and losses can be better appreciated in referring to Fig. 3.

* See page 12.

FIG. 3 GROSS PROFITS BEFORE TAX (MiO FF)

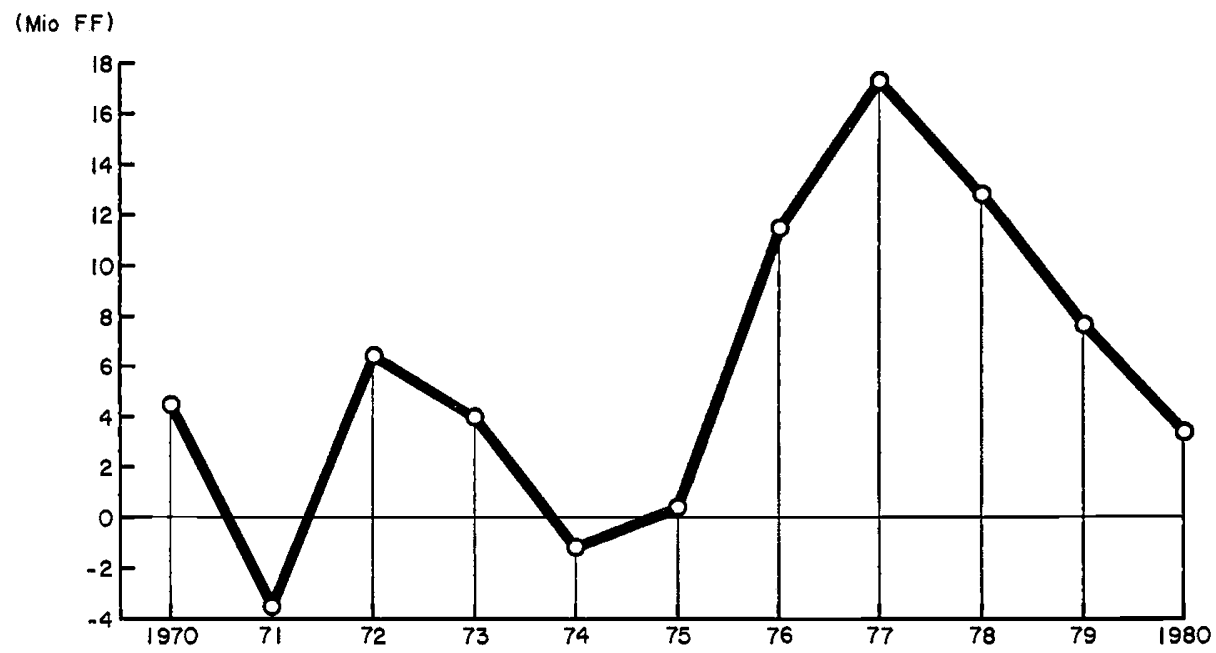


Improvement in profits corresponds to the stabilization of inflation in 1975 and its subsequent reduction in 1976 and in 1977. Although the inflation rate remains at its 1977 level as of 1978, profits are deteriorating as of the same year.

This can be accounted for by the decline in the price of premiums as of 1977 which reach the inflation rate in 1979, whereas the cost of claims continues to increase at a steady rate of about $9.5 \%$ as of 1976 , i.e. at an annual rate of $3.5 \%$ over the inflation rate (see Fig. 4).

This explains why the situation is much worse than what most of the indicators for 1979 tend to show. True, profits in 1979 appear to be at a normal level, the return on capital invested being as high as in 1970; the solvency margin is satisfactory and the claims over premiums ratio (the loss ratio) reaches the level observed during the historical run. Only

FIG. 4 INCREASES IN PREMIUM PRICE VERSUS INCREASES IN PRICE OF CLAIMS (in \%)

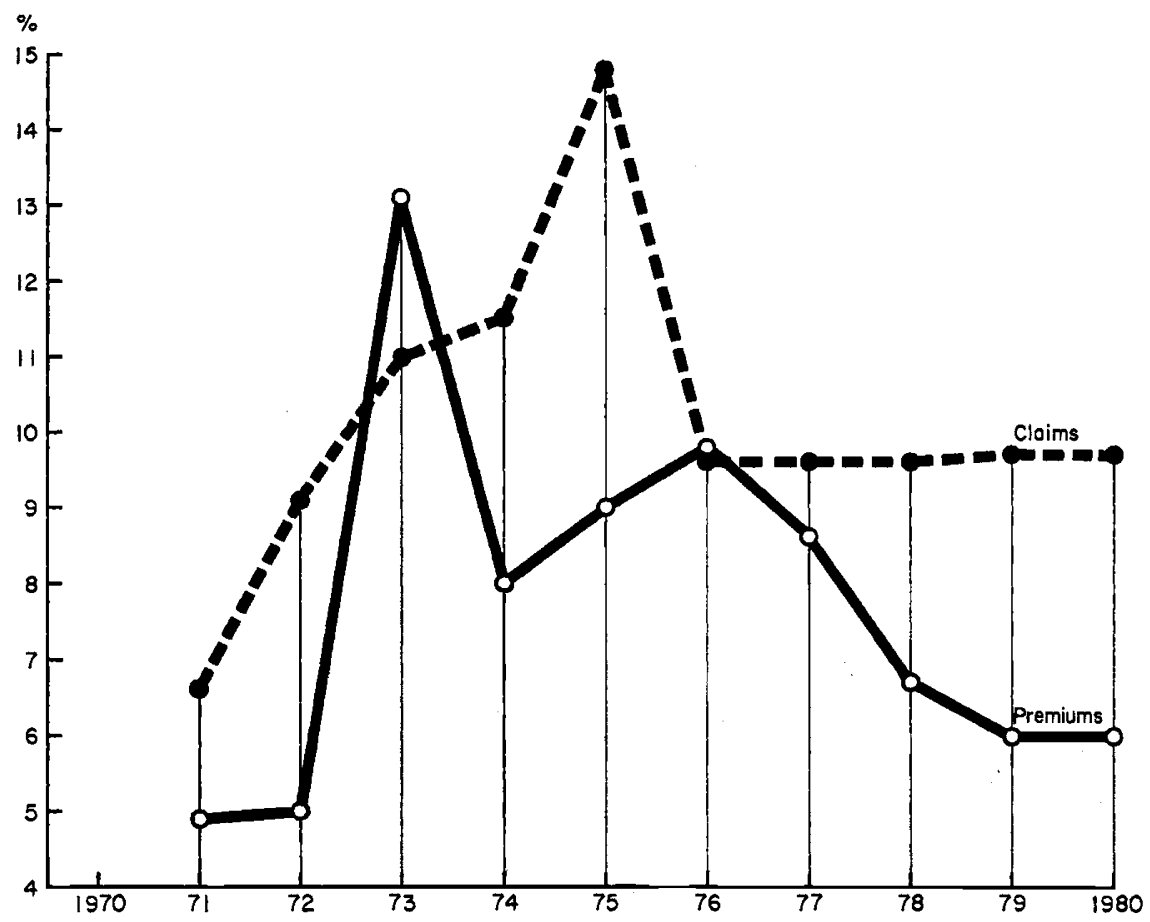


the ex-post cost of claims ratio shows a profound imbalance which precisely refers to the superimposed claim inflation ${ }^{1}$.

Since we have assumed inflation to remain at its 1977 level for the subsequent years, there is no place for adjustment in premiums price. Hence the catastrophic situation of the company in 1985. Its net worth would have declined to reach practically its 1974 level. At current prices, premiums earned would have been doubled, outstanding claims multiplied by a 2.6 factor. Of course, the company would probably not have continued its operations up to 1985 under these circumstances.

\section{The simulation runs}

The above analysis was made by the participants in the simulation exercise. The evident objective for this exercise was to avoid the decline in profits expected to occur as of 1974.

A list of 6 alternative actions was established for this purpose, namely :

1. to increase the price of premiums at a higher level than inflation,

2. to reduce the time delay for adjusting premiums price to inflation,

3 . to reduce annual wage increases to the inflation rate,

4. to continue to increase the number of policies at the historical rate observed during the period 1970-1974,

5. to reduce delays in claims settlement,

6. to renounce increasing provisions for outstanding claims when cost of claims grows at an annual rate higher than 9.5 per cent (discard of the 1973-1975 peak).

It was judged desirable to increase the price of premiums at a higher level than inflation (action 1) because cost of claims depending mostly on wage rates (cost of repairs and medical cares) are rising faster than the general inflation rate. Reducing the time delay (action 2) for adjusting premium price to inflation, which was assumed in standard run to be $1 \frac{1}{2}$ year, is not very realistic for actuarial and administrative reasons. Reducing annual wage increases (action 3) would have been in line with the zero growth assumption. This action was retained for a subsequent simulation exercise. To renounce increasing provisions for outstanding claims during the peaks of claims inflation (action 6) would have required some delicate manipulations or change in the computer programme.

1 On this subject, see Gunnar BENKTANDER: "Inflation and Insurance : measuring the problem and facing it" in Reinsurance, April 1975. 
For these various reasons, only actions 1,4 and 5 were retained. The reduction of delays in claims settlement (action 5) was tested for one insurance type. The impact of such an action is practically limited to one year only and has proved to be marginal. We will then present data results only for actions 1 and 4.

The practical meaning of adjusting premium prices to cost of claims (action 1) was to increase the annual price increase $3 \%$ over its previous level as from 1976 (see Fig. 5).

Alternatively, action 4 aimed tentatively to compensate for low premium prices by continued growth at $3 \%$ per year.

According to the evolution of gross profits before tax which are given in fig. 6 , action 1 appears successful in maintaining a high profitability. On the other hand, action 4 is of limited significance for attaining the same objective.

A closer look at the evolution of the six indicators for typical years (Table 2) shows some additional interesting features.

FIG. 5 INCREASES IN PREMIUM PRICE VERSUS INCREASES IN PRICE OF CLAIMS (in \%)

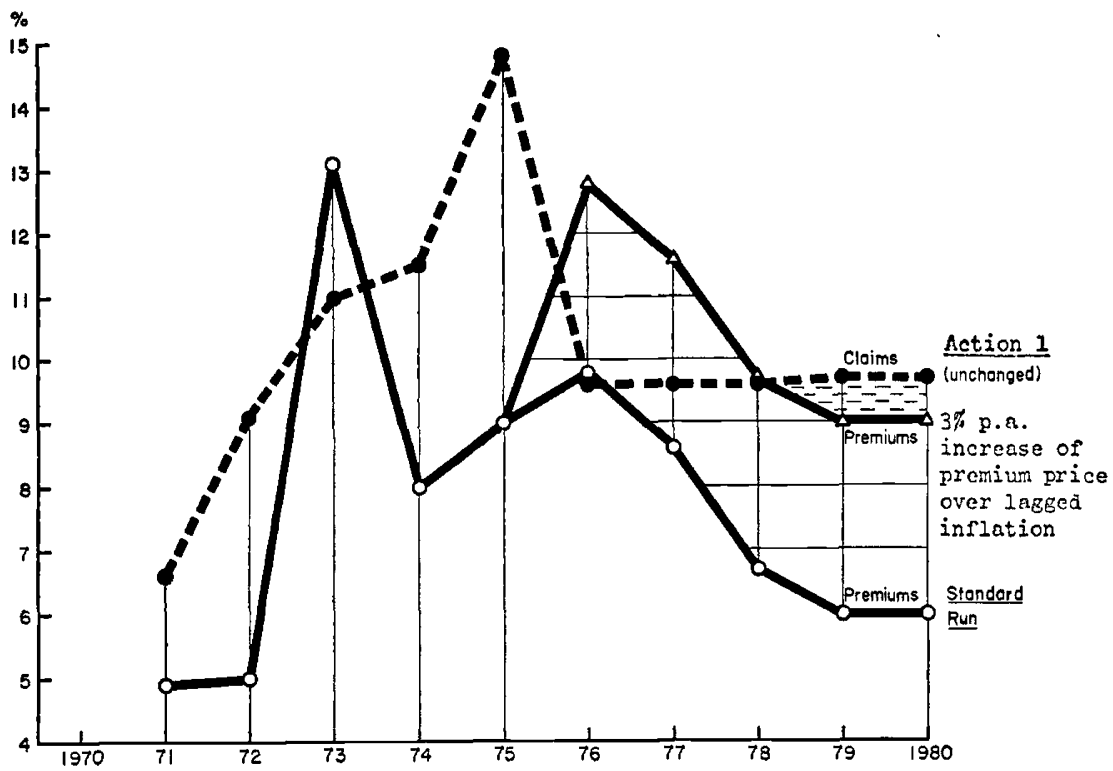


With action 1 the solvency margin is rapidly improving. However the rate of gross return on invested capital tends to stabilize around $13 \%$.

With action 4 the solvency margin never reaches a satisfactory level, even during the 1977-1980 period when profits reach an acceptable level (as indicated by the gross return on invested capital).

In the long run, action 4 (continued growth) exerts an additional pressure on profitability and solvency margins. This confirms that business conditions of the standard run are unacceptable, i.e. that insurance companies cannot continue to support the historical superimposed claims inflation without increasing premiums price over the inflation rate. It further shows that growth in business volume constitutes no way out of this situation.

The explanation why growth is no solution to the cost of claims pressure is given by the evolution of provisions as portrayed in fig. 7 . Increase in business volume leads to an increase in premiums earned which are absorbed by additional provisions (see also Annexes 2 and 3).

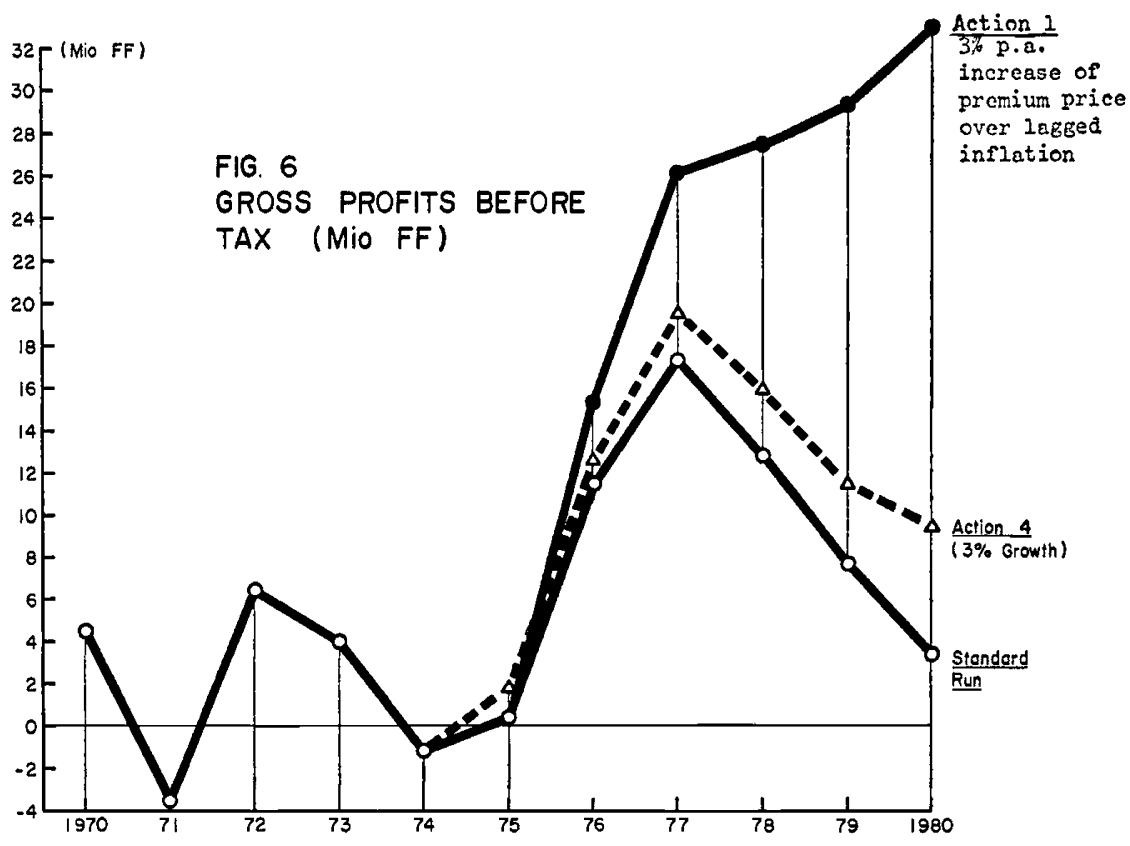


Table 2 Main Indicators for the Standard Run and the Simulations with Action 1 and Action 4

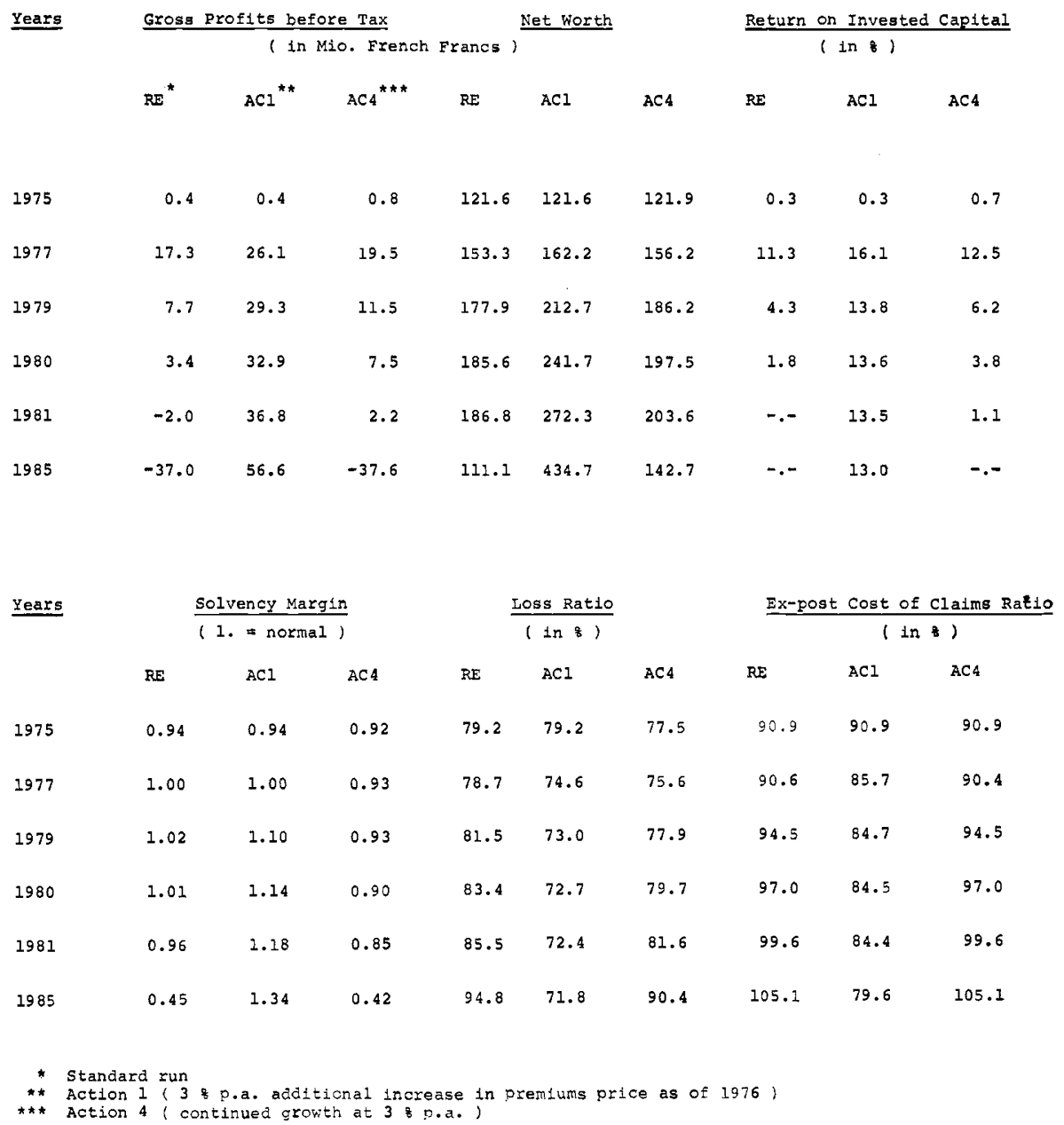


FIG. 7 CHANGES IN PROVISIONS (Mio FF)

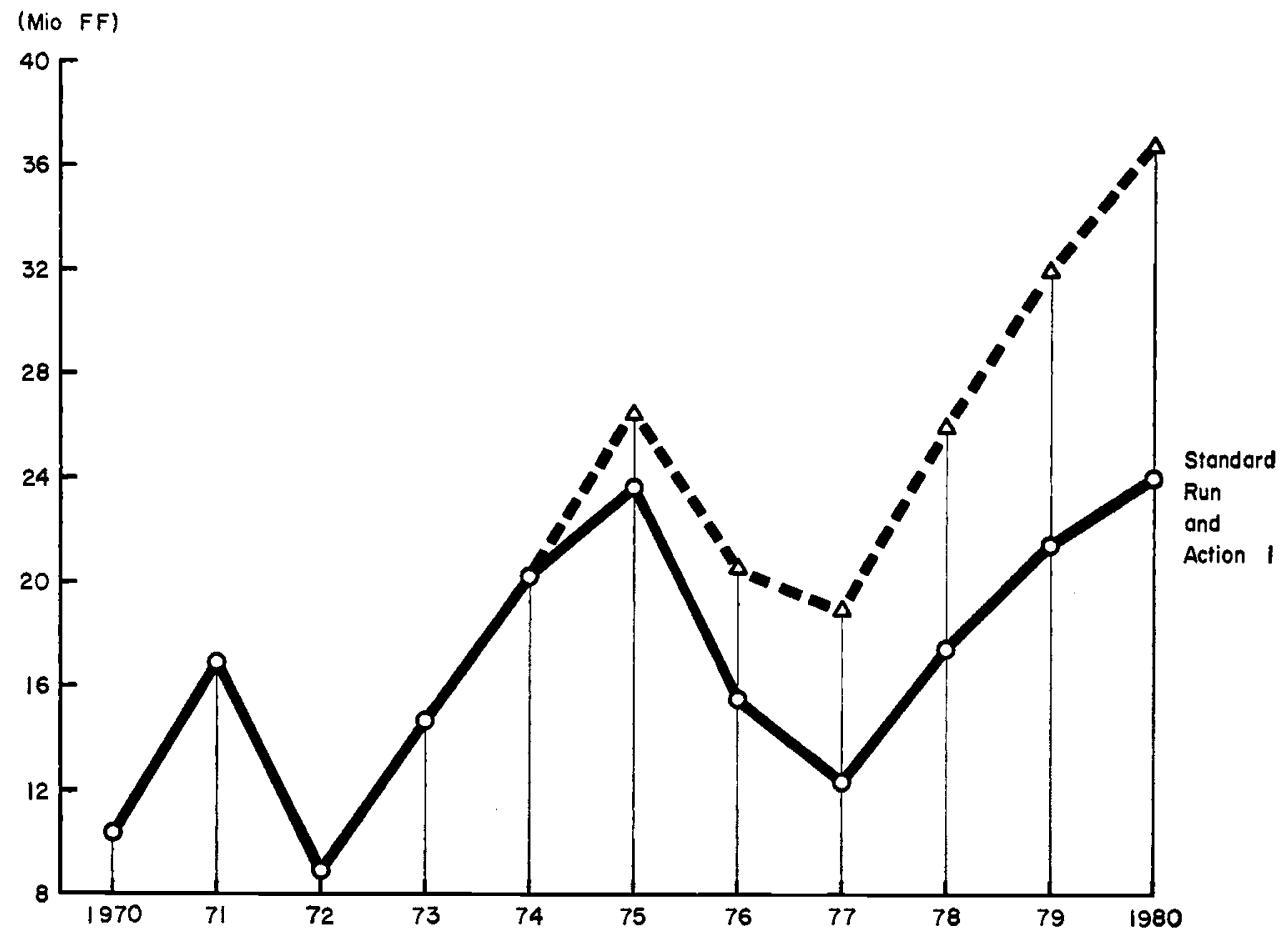

VI. GENERAL CONCLUSION

ON THE USE OF SIMULATION MODELS

IN INSURANCE BUSINESS

The reported simulation exercise and other preliminary ones have permitted a new approach to the problems raised by inflation in the insurance business. Through this approach some phenomena have been analysed in a quantitative way and alternative solutions tested. From the simulations it seems that the insurance business is more sensitive to change in inflation rate rather than to its actual level. Another interesting situation has been pointed out : the necessity of adapting the premiums price after an increase in the cost of claims becomes evident only years later, when a corrective action is practically too late to be effective. In relation to this phenomenon, the relevance of various indicators has been tested. 
The ex-post cost of claims ratio has shown to be very sensitive to external changes.

These results obtained with the aid of a simplified model give an idea of the possible uses of more complex models specifically adapted to the needs of a company.

The model developed for the reported simulation exercise has allowed the possibility of understanding some of the mechanisms of the insurance business more fully and of more clearly visualizing how inflation modifies the corporate financial balance. This model can be further used for enriching a learning process and helping insurers to become acquainted with more complex mathematical tools. It could also be used as an instrument for theoretical reflections on the structure of insurance business and its possibilities of adaptation to environmental changes.

For the sake of simplicity and in order to highlight the most important features of the problem of inflation, some of the variables that are not directly linked to inflation have been kept exogenous. Further development of the model could aim at solving specific needs of a company and developing some links between variables, such as, for instance :

- a sub-model describing the adjustment of premiums to the frequency, the nature and cost of damages,

- a sub-model calculating the sales and purchases of investment in function of their return and their market prices, taking into account the constraints specific to an insurance company.

More sophisticated indicators that could be more relevant and more useful to managers could also be developed on the basis of the experience gained through the reported simulation exercise. 


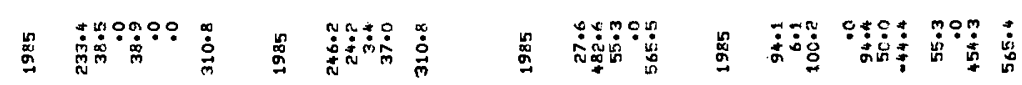

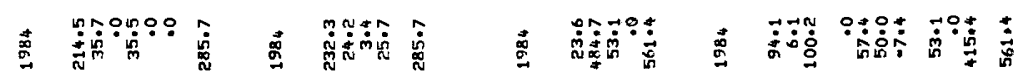

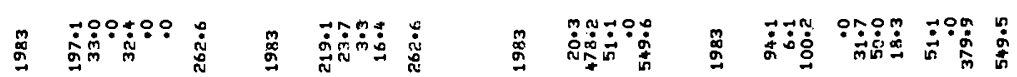

雚

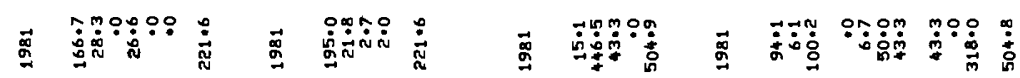

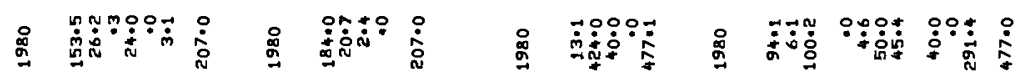

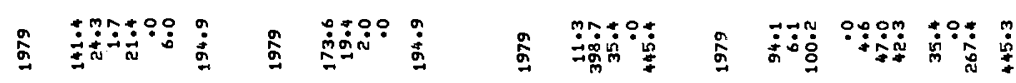

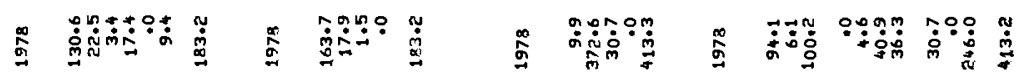

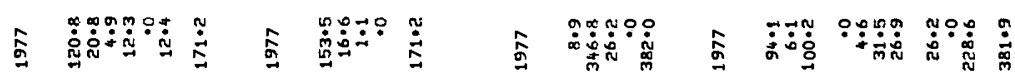

L̊

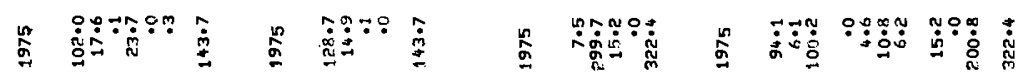

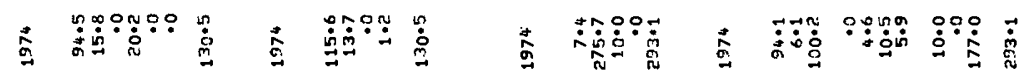

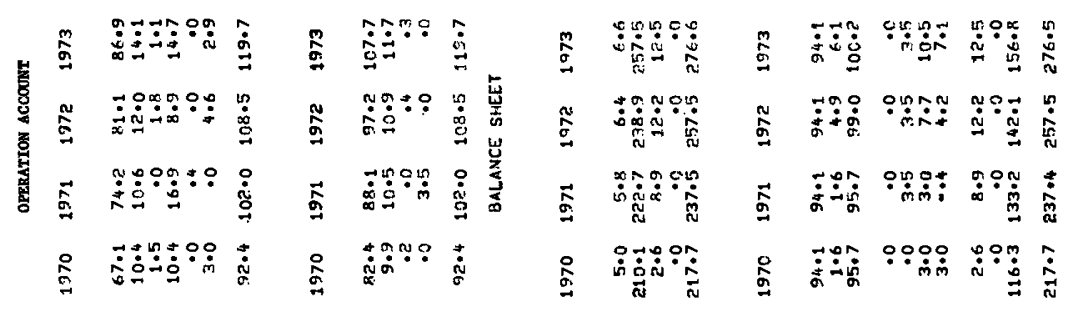

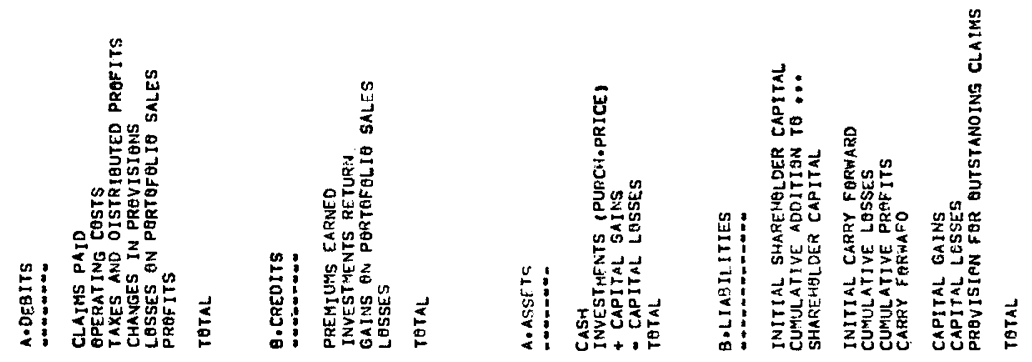




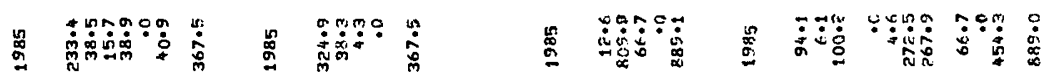

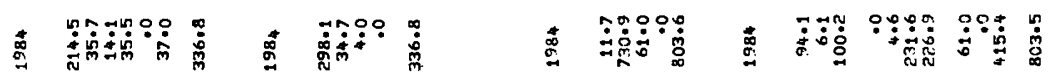

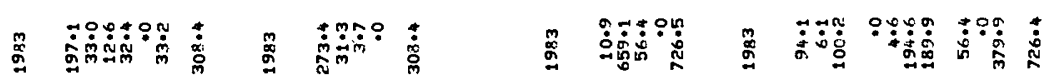

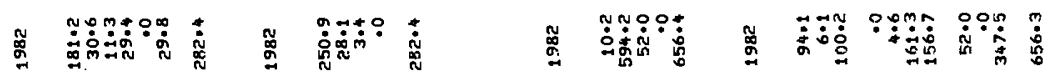

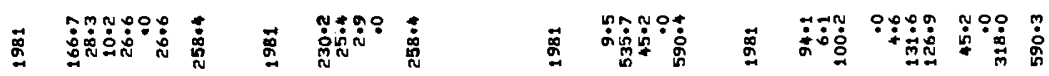

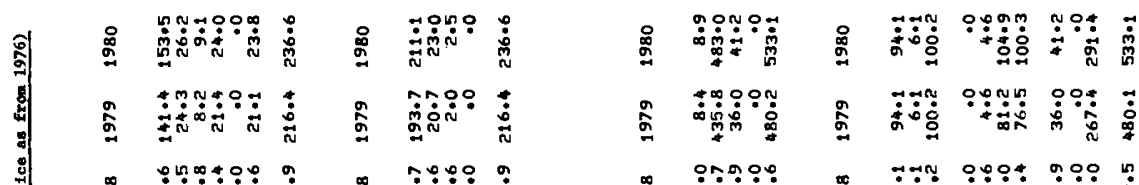

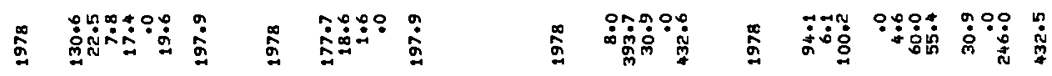

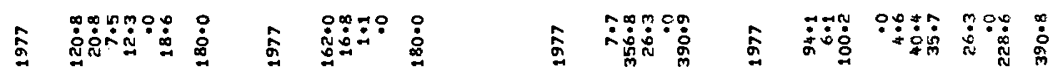

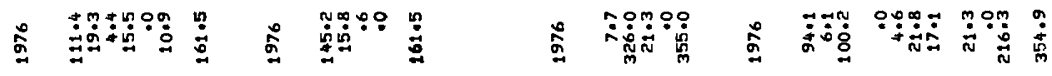

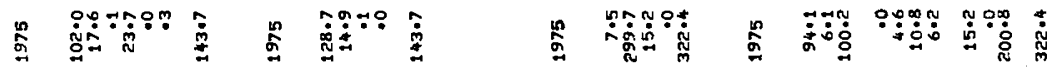

莫

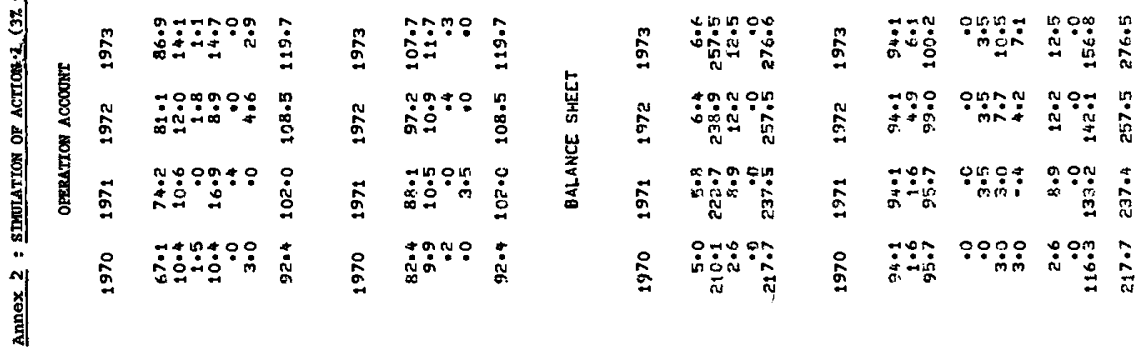

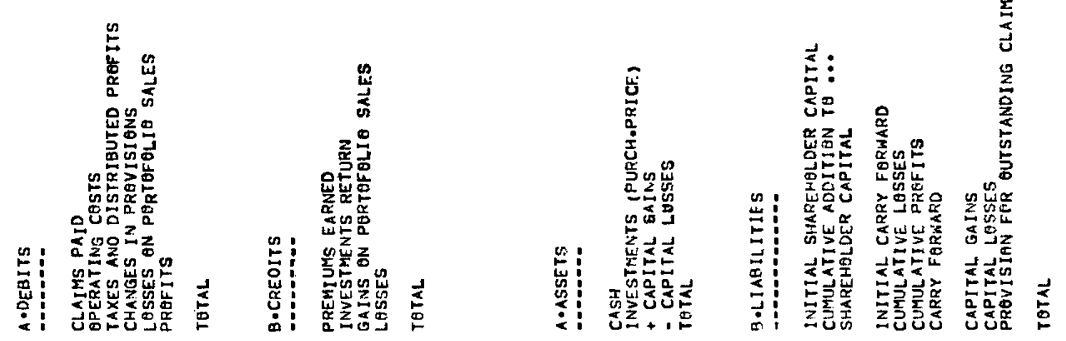




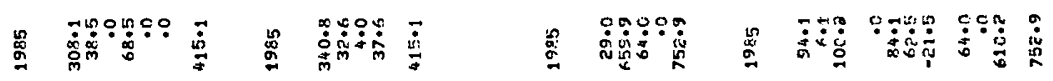

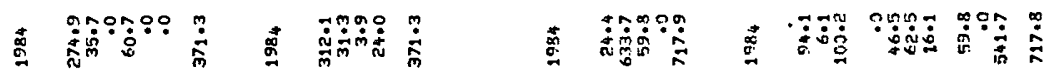

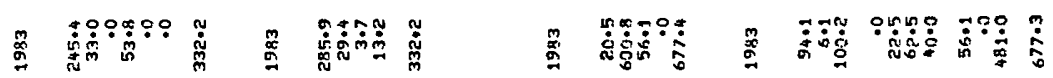

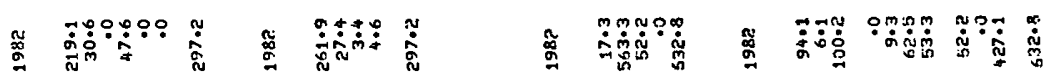

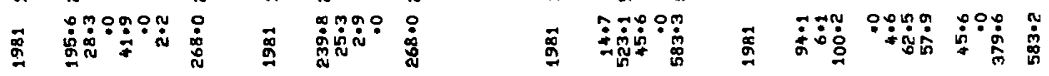

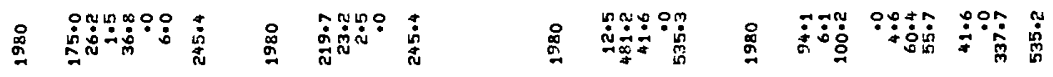

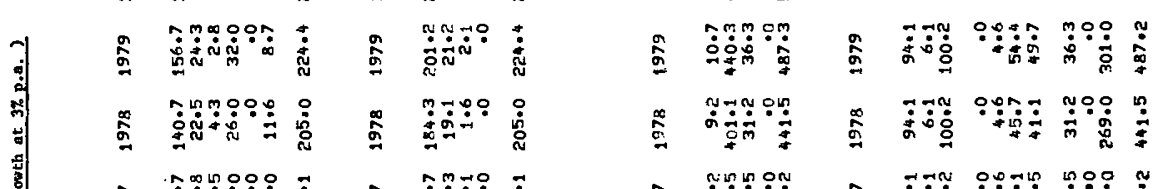

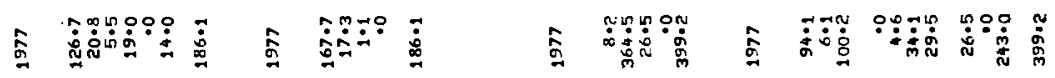

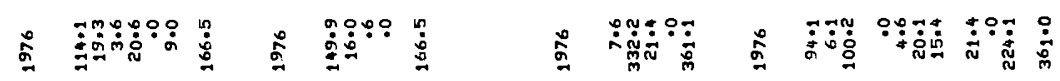

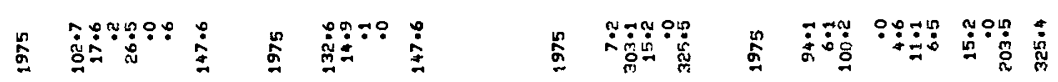

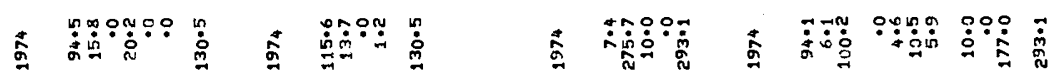

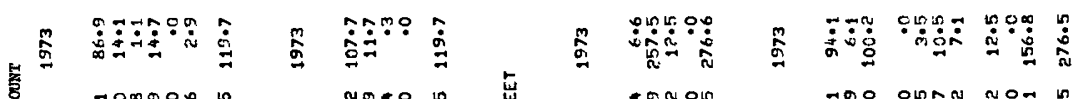

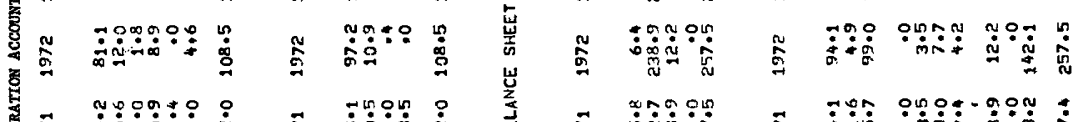

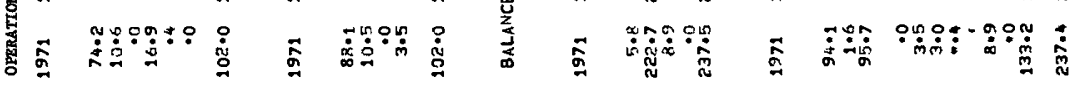

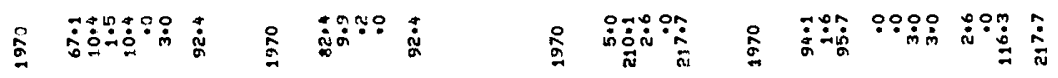
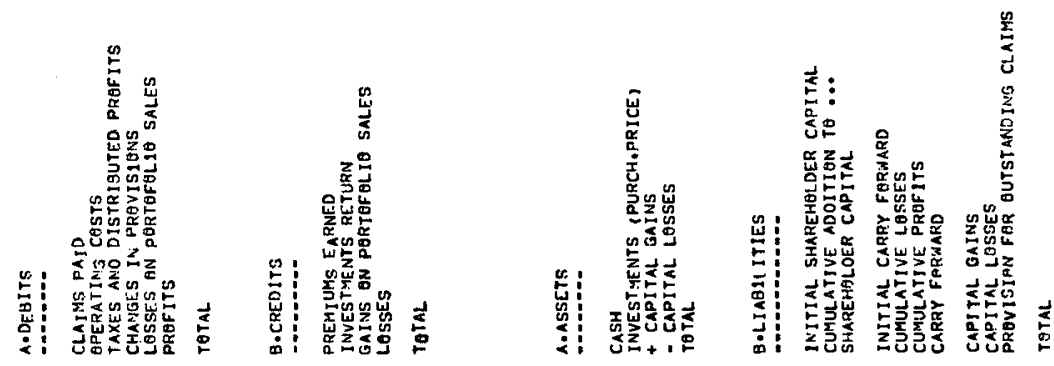